\title{
Dexamethasone and Basic-Fibroblast Growth Factor Regulate Markers of Mineralization in Cementoblasts In Vitro
}

Sema S. Hakki, * Rahime M. Nohutcu ${ }^{\dagger}$ Erdogan E. Hakki, ${ }^{\ddagger}$ Janice E. Berry, ${ }^{\S}$ Mahinur S. Akkaya,॥ and Martha J. Somerman"

Background: The aim of this study was to determine the effects of basic-fibroblast growth factor (b-FGF) and/or dexamethasone (Dex) on cementoblasts in vitro.

Methods: Murine cementoblasts were treated as follows: 1) $5 \%$ FBS (fetal bovine serum) + ascorbic acid (AA, $50 \mu \mathrm{g} / \mathrm{ml}$, control); 2) $5 \%$ FBS+Dex $\left(10^{-7} \mathrm{M}\right)+\mathrm{AA}$; 3$) 5 \%$ FBS+b-FGF $(50 \mathrm{ng} / \mathrm{ml})+\mathrm{AA}$; or 4$) 5 \%$ FBS+Dex $\left(10^{-7} \mathrm{M}\right)+\mathrm{b}$-FGF $(50 \mathrm{ng} / \mathrm{ml})+\mathrm{AA}$ and then evaluated by Northern analysis for changes in specific genes and by von Kossa stain for changes in mineral nodule formation.

Results: Mitotic activity: b-FGF stimulated DNA synthesis significantly versus negative control. Gene expression: osteocalcin (OCN): Dex or b-FGF or the combination resulted in a decrease in expression versus control. Bone sialoprotein (BSP): Dex increased expression of BSP mRNA levels, b-FGF decreased transcript for BSP at 6 and 24 hours. Long-term (8 days) Dex, b-FGF, or Dex plus b-FGF caused a decrease in BSP expression versus control; osteopontin (OPN): both Dex and b-FGF increased transcripts for OPN seen by 6 hours, with a greater increase noted with b-FGF versus Dex. No apparent additive effect of Dex with b-FGF was noted; matrix gamma-carboxyglutamic acid protein (MGP): b-FGF induced transcripts for MGP and addition of Dex increased this effect, while Dex alone had no effect on expression. Biomineralization: Dex increased cementoblast-mediated biomineralization, while b-FGF blocked this activity, and addition of Dex to b-FGF did not alter FGF associated inhibition.

Conclusion: Dex and FGF alone and in combination alter cementoblast behavior, but additional studies are required to determine whether these factors have beneficial effects at the clinical level. J Periodontol 2005;76:1550-1558.

\section{KEY WORDS}

Dental cementum; dexamethasone; growth factors, fibroblast.

\footnotetext{
* Selcuk University, Faculty of Dentistry, Department of Periodontology, Konya, Turkey.

$\dagger$ Hacettepe University, Faculty of Dentistry, Department of Periodontology, Ankara, Turkey.

\# Selcuk University, Faculty of Agriculture, Department of Field Crops, Konya.

$\S$ Department of Periodontics/Prevention/Geriatrics, University of Michigan, School of Dentistry, Ann Arbor, MI.

|| Middle East Technical University, Biotechnology Program, Ankara, Turkey.

Il Department of Periodontics, University of Washington, School of Dentistry, Seattle, WA.
}

primary goal of periodontal
research is to increase our under-
standing of principles governing cell behavior and to apply this knowledge to design predictable and successful therapies for promoting regeneration of lost periodontal tissues. In this regard, several studies have focused on determining the mechanisms by which polypeptide growth and differentiation factors modulate development and regeneration of periodontal tissues. ${ }^{1-4}$ Growth factors play a critical role in the periodontal wound healing process by stimulating and regulating numerous cell activities including mitogenesis, chemotaxis, metabolism, and differentiation. ${ }^{5-10}$

Findings based on in vitro and in vivo studies suggest that growth and differentiation factors can be used alone or in combination as therapeutic agents for restoring tooth-supporting structures destroyed by periodontitis. ${ }^{1,8,9-12}$ Factors considered to have a positive impact on periodontal regeneration include platelet-derived growth factor (PDGF), insulin-like growth factor (IGF), fibroblast growth factor (FGF), and the transforming growth factor (TGF) superfamily. 1,4,6,12 Among these factors, basic-fibroblast growth factor (b-FGF) has been identified as a positive factor for bone regeneration and angiogenesis, ${ }^{13}$ but limited data exist regarding the effect of FGF alone or in combination with other growth/ differentiation factors on cells associated with periodontal tissues and specifically on cementoblasts. 
Basic-fibroblast growth factor (b-FGF, FGF-2) has numerous biologic activities that include stimulation of cell growth, migration, angiogenesis, wound healing, tissue repair, differentiation, and morphogenesis. ${ }^{14,15}$ $\mathrm{b}-\mathrm{FGF}$ is a potent mitogen for bone cells derived from embryonic chick calvaria, newborn mouse calvaria, bovine bone, and rat calvaria. ${ }^{16,17}$ Also, b-FGF stimulates proliferation and differentiation of chondrocytes in vitro and promotes cartilage repair in vivo. ${ }^{17}$ It has been demonstrated that gene expression for FGF receptor type I, a receptor for b-FGF, is rapidly upregulated after femur fracture in rats, and that FGF signaling has multifunctional roles during fracture healing and may regulate both osteoblasts and osteoclasts, contributing to bone formation and remodeling. ${ }^{18}$ Shimazu et al. indicated that human periodontal ligament (PDL) cells express syndecan 2, 4, and FGFR1 mRNA and showed that these molecules are downregulated in cells during maturation in culture. ${ }^{19}$ This effect may have implications in the control of growth and differentiation of PDL cells during development and regeneration. ${ }^{19}$ Takayama et al. reported that PDL cells express b-FGF receptors (b-FGFR) and b-FGF has a potent mitogenic effect on PDL cells, especially on undifferentiated cells. ${ }^{20,21}$ b-FGF is produced primarily by PDL fibroblasts and endothelial cells within the periodontal region and b-FGF levels have been reported to decrease in tissues associated with chronic periodontal lesions. ${ }^{22}$ Using animal models (beagle dogs and primates), researchers have shown that local application of b-FGF enhances periodontal regeneration. ${ }^{23-26}$ These findings suggest that b-FGF plays an important role in controlling the behavior of connective tissues, participating in healing and regeneration processes, and that b-FGF has potential therapeutic applications, most likely due to angiogenic and growth promoting effects. ${ }^{27,28}$

The potent synthetic glucocorticoid dexamethasone (Dex) has been shown to act synergistically with growth factors, such as platelet derived growth factorBB/AA (PDGF-BB, AA), to enhance mitogenesis of gingival, periodontal ligament and pulp fibroblasts in vitro. ${ }^{29}$ In vivo studies have shown that PDGF and Dex combined within a collagen matrix, when applied to periodontal defects, induce regeneration of the periodontium, using a monkey model. ${ }^{30}$ Dex has been demonstrated to increase parathyroid hormone (PTH)mediated cyclic adenosine monophosphate (cAMP) response in periodontal ligament cells, when compared with cells treated with PTH alone in vitro. ${ }^{31}$ Pitaru et al. indicated that b-FGF has the capacity to stimulate glucocorticoid receptors and subsequently the growth and biochemical function of rat stromal bone marrow cells in vitro, and the addition of b-FGF to Dex treated bone marrow cells resulted in a considerable increase in mineral nodules. ${ }^{32-34}$ b-FGF has been shown to enhance growth, osteogenic phenotype, and mineral formation in Dex stimulated human bone marrow derived bone-like cells in vitro. ${ }^{35}$

Although the biological effects of b-FGF on human periodontal cells have been investigated, no studies have been directed at determining the effects of FGF on cementoblasts, considered important cells for periodontal regeneration. The objective of this study was to determine the effects of b-FGF and/or Dex on cementoblast behavior including the ability to alter genes associated with extracellular matrix formation and cementoblast mediated mineral nodule formation in vitro.

\section{MATERIALS AND METHODS}

\section{Cell Culture}

An immortalized cementoblast cell line was used for these studies and methods for isolating these cells have been published. ${ }^{36-38}$ Briefly, cells were obtained using osteocalcin (OC) promoter driven SV40 T antigen transgenic mice (OC-TAg), provided by Dr. Jolene Windle (Department of Human Genetics, Medical College of Virginia School of Medicine, Richmond, Virginia). ${ }^{39}$ Cells expressing osteocalcin, root surface cells (cementoblasts), but not periodontal ligament (PDL) fibroblasts, are immortalized, and thus only cementoblasts, not PDL cells, survive in vitro. Mandibular first molars of mice at day 41 of development (Day 0 = vaginal plug day) were used to obtain cells. All procedures described above were approved by the University of Michigan Committee and the Unit for Laboratory Animal Medicine (ULAM), and were compliant with state and federal laws as well as the guiding principles of Use and Care of Animals. This time point was selected based on previous studies in situ, which demonstrated that day 41 cementoblasts; i.e., cells along the root surface, but not PDL cells, express markers of mature osteoblasts/cementoblasts; e.g., BSP and OCN mRNA. Cells were termed OC promoter cementoblasts (CM) (OC-CM cells). ${ }^{38}$

Mandibulae of mice were dissected and first molars removed using a dissecting microscope to separate PDL from surrounding alveolar bone. Collagenase/trypsin cocktail digestion was used to release cementoblasts from the surface of first mandibular molars. ${ }^{36}$ Cells were maintained in Dulbecco's modified Eagle's medium (DMEM), " supplemented with $10 \%$ fetal bovine serum ${ }^{\#}$ (FBS) containing $100 \mathrm{U} / \mathrm{ml}$ penicillin ${ }^{\#}$ and $100 \mu \mathrm{g} / \mathrm{ml}$ streptomycin $^{\#}$ in a humidified atmosphere of $5 \% \mathrm{CO}_{2}$ at $37^{\circ} \mathrm{C}$. Cells used in these experiments were between the 10 th and 15 th passages.

\section{DNA Synthesis Assay}

The effects of different concentrations of b-FGF** on DNA synthesis were assayed by $\left[{ }^{3} \mathrm{H}\right]$-thymidine incorporation. The concentrations of b-FGF used were

\# Invitrogen, Gaithersburg, MD.

* * Sigma-Aldrich Chemicals, St. Louis, MO. 
$0.1 \mathrm{ng} / \mathrm{ml}, 1 \mathrm{ng} / \mathrm{ml}, 10 \mathrm{ng} / \mathrm{ml}$, and $100 \mathrm{ng} / \mathrm{ml}$. Doses selected were based on previous studies examining the effect of b-FGF on periodontal ligament and bone-like cells, in culture. ${ }^{21,33}$ DNA synthesis assays were performed as previously described. ${ }^{5}$ Serum-free DMEM was used as a negative control and 10\% FBS, where FBS is known to contain various growth factors including b-FGF, was used as a positive control. Cells were plated in 24multiwell plates ${ }^{\dagger \dagger}$ at a density of $5 \times 10^{4}$ cells/well in triplicate and incubated for 24 hours in DMEM containing $10 \%$ FBS and antibiotics. Media were aspirated, cells were rinsed twice with phosphate buffered saline (PBS), and serum-free DMEM was added with and without b-FGF at selected doses. Cells were incubated for 20 hours, and then $3 \mu \mathrm{Ci} / \mathrm{ml}$ methyl ${ }^{3} \mathrm{H}$ thymidine ${ }^{\ddagger} \neq$ was added to each well for the last 4 hours of the 24-hour experiment. Next, cells were rinsed with PBS and then incubated with $5 \%$ trichloroacetic acid (TCA) for 1 hour at $4^{\circ} \mathrm{C}$. TCA was removed and $1 \%$ sodium dodecyl sulfate (SDS) added to the wells and incubated for 1 hour at $55^{\circ} \mathrm{C}$. The precipitate was transferred into scintillation liquid and activity was counted in a scintillation counter. ${ }^{\S \S}$

\section{Morphology}

Cells were allowed to adhere for 24 hours in DMEM with $10 \%$ FBS, after which media were changed to DMEM with $5 \%$ FBS containing ascorbic acid (AA, $50 \mu \mathrm{g} / \mathrm{ml}$ ) and b-FGF $(50 \mathrm{ng} / \mathrm{ml})$, Dex** $\left(10^{-7} \mathrm{M}\right)$, or b-FGF $(50 \mathrm{ng} / \mathrm{ml})+\operatorname{Dex}\left(10^{-7} \mathrm{M}\right)$. Media with $5 \%$ FBS and $5 \%$ FBS+AA served as controls. The optimum concentration of Dex $\left(10^{-7} \mathrm{M}\right)$ was selected based on previous studies with human osteoblasts and PDL cells. ${ }^{40-42}$ Cells were maintained 8 days, changing media every 2 days, for evaluation of morphology. Images of cementoblasts treated with different components were examined visually using phase contrast microscope ${ }^{\|\|}$on day 8 of treatment.

\section{Northern Blot Analysis}

To determine gene expression, OC-CM cells were plated in $100 \mathrm{~mm}$ cell culture dishes ${ }^{\dagger \dagger}$ at $5 \times 10^{4}$ cells $/ \mathrm{cm}^{2}$ and treated after 24 hours as described above. Media with $5 \%$ FBS+AA served as control. Total RNA was isolated with Trizol $^{\#}$ at 1,6 , and 24 hours and days 3 and 8. RNA concentration was quantified by spectrophotometer. RNA $(5 \mu \mathrm{g})$ was denatured, fractionated on $6 \%$ formaldehyde, $1.2 \%$ agarose gel, transferred to nylon membrane, If and cross-linked by UV radiation."\# Blots were hybridized with random primed ${ }^{32} \mathrm{P}$-labeled probes ${ }^{\ddagger \dagger}$ and were exposed to film with intensifying screens at $-70^{\circ} \mathrm{C}$ for 24 to 48 hours. Probes used for Northern blots were $\mathrm{BSP}=\mathrm{M}$-BSP consisting of $1 \mathrm{~kb}$ of mouse cDNA in PCR II $^{43}$ (a gift from Drs. M. Young and L. Fisher, National Institute of Dental and Craniofacial Research, Bethesda, Maryland); OPN = MOP-3 consisting of $1 \mathrm{~kb}$ of mouse OPN cDNA in PCR II ${ }^{44}$ (a gift from Drs. M. Young, and L. Fisher); OCN $=400$ bp of mouse OCN cDNA in pSP65 cloning vector ${ }^{45}$ (obtained from Dr. J. Wozney, Genetic Institute, Cambridge, Massachusetts); $M G P=$ consisting of $398 \mathrm{bp}$ of mouse MGP cDNA in Bluescript cloning vector (obtained from Dr. Gerard Karsenty, Department of Molecular and Human Genetics, Baylor College of Medicine, Houston, Texas). ${ }^{46}$ Experiments were carried out twice. An image analysis program was used to quantify the data, which were normalized to ethidium bromide gel $18 \mathrm{~S}$ bands.

\section{Mineralization Assay}

Cells were plated at $5 \times 10^{4}$ cells $/ \mathrm{cm}^{2}$ in 24 -well plates in DMEM containing 10\% FBS. After 24 hours, cells were exposed to the following factors: 1$) 5 \% \mathrm{FBS}+\beta$-glycerophosphate (10 mM); 2) 5\% FBS+mineralization media $(\mathrm{MM}=$ ascorbic acid [AA, $50 \mu \mathrm{g} / \mathrm{ml}]$ and $\beta$-glycerophosphate [BGP, $10 \mathrm{mM}])$; 3) 5\% FBS+Dex $\left(10^{-7} \mathrm{M}\right)+\mathrm{MM}$; 4) $5 \%$ FBS+b-FGF (50 ng/ml)+MM; and 5) 5\% FBS+Dex $\left(10^{-7} \mathrm{M}\right)+\mathrm{b}-\mathrm{FGF}(50 \mathrm{ng} / \mathrm{ml})+\mathrm{MM}$. Induction of mineralization was determined on day 8 by von Kossa staining. ${ }^{47,48} \mathrm{~A}$ representative experiment is shown, where results were reproduced in three separate experiments.

\section{Statistical Analysis}

For DNA synthesis assay, the statistical analysis used was one-way analysis of variance (ANOVA) and Tukey Kramer multiple comparison tests. The data are represented as mean \pm standard deviation.

\section{RESULTS}

\section{DNA Synthesis Assay (Fig. 1)}

To determine the mitogenic response of cementoblasts to $\mathrm{b}-\mathrm{FGF}$, a $\left[{ }^{3} \mathrm{H}\right]$ thymidine incorporation assay was performed. When compared with control (serum-free DMEM) b-FGF increased DNA synthesis in cementoblasts in a dose-dependent fashion with a significant increase in proliferation noted at a concentration of $10 \mathrm{ng} / \mathrm{ml}$. The highest $\left[{ }^{3} \mathrm{H}\right]$ thymidine incorporation, 2 -fold increase over control, was seen at the concentration $100 \mathrm{ng} / \mathrm{ml} \mathrm{b-FGF}$. Based on these results, we selected $50 \mathrm{ng} / \mathrm{ml}$ b-FGF for gene expression and mineralization experiments. Previous in vitro studies by our group ${ }^{42}$ and others ${ }^{40}$ reported no effect of Dex on DNA content for periodontal cells and osteoblasts, respectively.

\section{Cell Morphology (Fig. 2)}

Cementoblasts, under various treatment conditions, were examined visually on day 8 using a phase contrast microscope. "โा Differences in cell morphology were noted between groups. Cells from control cultures

\footnotetext{
$\dagger \dagger$ Falcon, Becton Dickinson, Franklin Lakes, NJ.

玤 Amersham-Pharmacia Biotech, Arlington Heights, IL.

$\S \S$ Wallac 1410, Pharmacia, Turku, Finland.

|l| Axiovert 35, Carl Zeiss, Inc., Thornwood, NY.

II Duralon-UV, Stratagene, Inc., La Jolla, CA.

\#\# Stratalinker, Stratagene, Inc.
} 


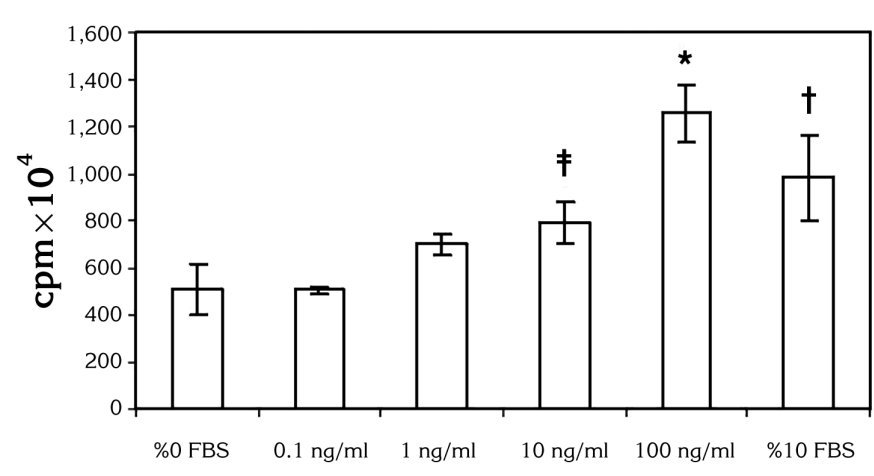

Figure $I$.

Effect of b-FGF concentration on DNA synthesis measured with

${ }^{3} \mathrm{H}$ thymidine incorporation (bar $=$ mean $\pm S D$ ). $* P<0.001: 100 \mathrm{ng} / \mathrm{ml}$ b-FGF>10 $\mathrm{ng} / \mathrm{ml}$, I $\mathrm{ng} / \mathrm{ml}, 0.1 \mathrm{ng} / \mathrm{ml}, 0 \%$ FBS. †P $<0.01: 10 \%$ FBS>0.1 ng/ml,

$0 \%$ FBS. $\neq \mathrm{P}<0.05: 100 \mathrm{ng} / \mathrm{ml}>10 \% \mathrm{FBS}, 10 \mathrm{ng} / \mathrm{ml}>0.1 \mathrm{ng} / \mathrm{ml}, 0 \% \mathrm{FBS}$. ules were noted (Fig. 2D). Cementoblasts treated with Dex + b-FGF + MM had more cuboidal appearance versus those treated with $M M+b-F G F$, but no mineral nodules were noted (Fig. 2E).

Northern Analysis: Short-Term mRNA Expression: 1, 6, and 24 Hours (Fig. 3)

BSP mRNA expression. At 1 hour, BSP expression for controls and Dex groups was similar, while cells exposed to b-FGF exhibited a decrease in BSP transcript that was not influenced by addition of Dex. At 6 and 24 hours, cells exposed to Dex exhibited an increase in BSP transcript.

OCN mRNA expression. OCN expression was downregulated in Dex, b-FGF and b-FGF+Dex groups when compared to control at all time periods examined. The inhibition of expression was greater than 3 -fold in FGF and FGF+Dex groups at 24 hours.

OPN mRNA expression. OPN mRNA levels were similar for all the groups at 1 hour. Cells exposed to b-FGF for 6 hours exhibited a dramatic increase (3-fold) in transcripts for OPN when compared to the expression in control or Dex treated cells. Addition of Dex to b-FGF treated cells did not alter this response. At 24 hours, Dex alone also increased OPN, but to a much lesser degree vs. b-FGF and b-FGF+Dex treated cells.

MGP mRNA expression. No detectable expression of MGP was noted at 1 hour under any of the treatment conditions. When compared to control cells, cells exposed to b-FGF or b-FGF+Dex for 6 hours exhibited increased transcript for MGP (5.9- and 11.4-fold greater, respectively). MGP mRNA expression was almost 2-fold higher in b-FGF+Dex treated cells when compared to treatment with b-FGF alone suggestive of an additive or synergistic effect. The expressions of transcripts for MGP were decreased by 24 hours, however increased levels of MGP in b-FGF or b-FGF+Dex treated cells were still evident.

Figure 2.

Phase contrast micrographs of OCCM cell cultures treated with $\boldsymbol{A}) 5 \% \mathrm{FBS}$; $\boldsymbol{B}) 5 \%$ $F B S+A A$; C) $5 \% F B S+A A+D e x$; D) $5 \% F B S+A A+b-F G F$; and E) $5 \% F B S+A A+D e x+b F G F$. Note cuboidal appearance for $A, B, C$, and E. Addition of b-FGF resulted in change in morphology of cementoblasts to a more fibroblastic appearance (D).

exhibited a cuboidal-type appearance, as previously reported for cementoblasts. ${ }^{37}$ Cells treated with $M M$ or MM plus Dex maintained a cuboidal morphology and mineral-like nodules were observed (Fig. 2B, 2C). No mineral-like nodules were noted in control cells treated with 5\% FBS alone (Fig. 2A). In contrast, cells exposed to $M M+b-F G F$ appeared densely packed, well organized, and more elongated (fibroblast-like) versus the other treatments, and no mineral-like nod-

\section{Long-Term mRNA Expression: Days 3}

(Fig. 4) and 8 (Fig. 5)

BSP mRNA expression. BSP mRNA expression was decreased markedly with b-FGF treatment at day 3 and addition of Dex did not alter this effect. At day 8 , decreased transcripts for BSP were still noted for b-FGF and b-FGF+Dex treated cells and Dex treated cells also showed a decrease in BSP expression versus untreated cells.

OCN mRNA expression. Effects of factors on OCN were similar to those seen at the earlier time points. At day 3, a marked decrease (9-fold) in expression of OCN was noted with b-FGF and addition of Dex did not 


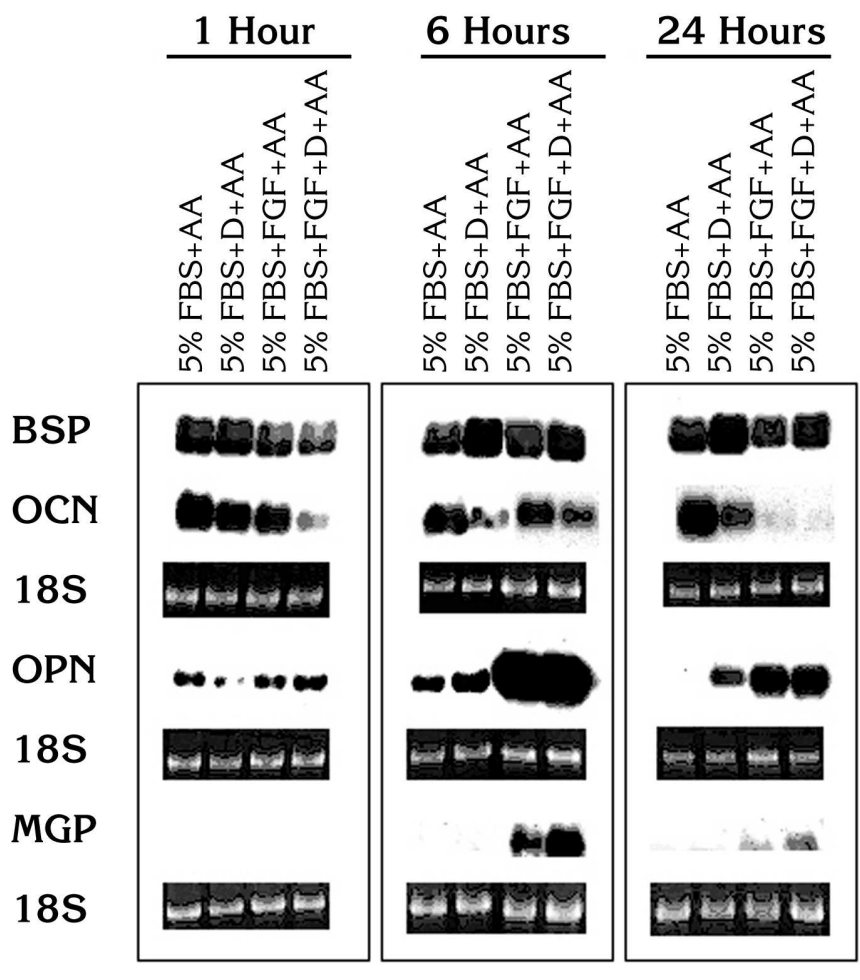

A
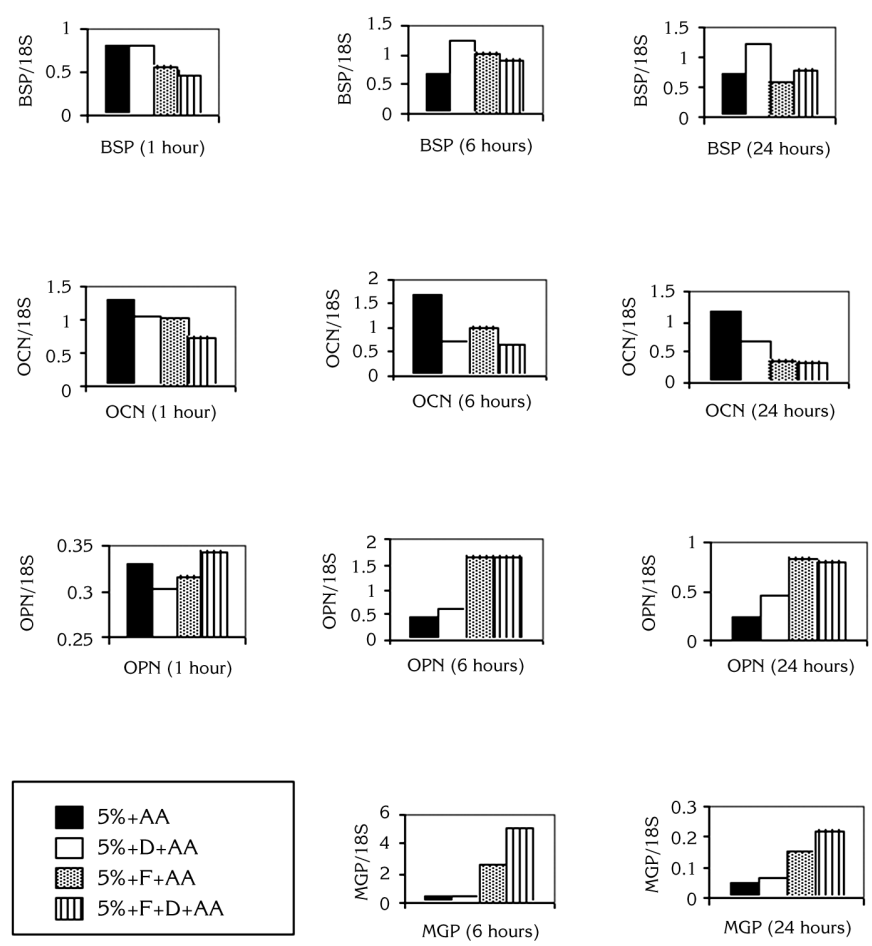

B

Figure 3.

Effect of Dex and/or b-FGF on gene expression by cementoblasts at I, 6, and 24 hours. A) Cementoblasts incubated in media containing 5\% $F B S+A A, 5 \% F B S+D e x+A A, 5 \% F B S+b-F G F+A A, 5 \% F B S+D e x+b-F G F+A A$, and RNA isolated at 1, 6, and 24 hours. Gene expression for BSP, OCN, OPN, and MGP was determined by Northern blot analysis. I 85 was used to evaluate loading efficiency. Note increased expression of OPN and MGP in cells exposed to b-FGF and Dex+b-FGF at 6 and 24 hours. Interestingly, b-FGF mediated increase in MGP mRNA expression was enhanced by Dex at both 6 and 24 hours. B) Normalization expressed as gene/l 8 S band (RNA gel). These results were noted in two separate experiments.

alter this response, an effect also seen at day 8. In Dextreated cells, there was a decrease of OCN transcripts at day 3 , which was seen to a greater extent at day 8.

OPN mRNA expression. Results were similar to those seen at early time points, an increased expression of OPN was observed in the Dex, and b-FGF and Dex+b-FGF groups versus untreated cells at day 3 . This increase was more dramatic in b-FGF (9-fold) and, again, addition of Dex had a minimal negative effect on this response. At day 8, a similar induction pattern of OPN mRNA expression was noted in all treated cells, but in this situation OPN induction was similar for both Dex and Dex+b-FGF treated cells, with a more marked effect for cells exposed to FGF only.

MGP mRNA expression. At day 3 an increase in MGP mRNA levels was observed in cells treated with b-FGF or Dex+b-FGF vs untreated cells (3- and 12-fold greater, respectively). MGP mRNA expression was dramatically higher in Dex+b-FGF treated cells (4-fold) versus b-FGF treated cells alone, thus suggesting an additive/synergistic effect. By 8 days, MGP transcripts were not detected under any of the conditions.

\section{Mineralization (Fig. 6)}

Dex treatment increased cementoblast-mediated biomineralization in vitro as determined by von Kossa staining when compared to untreated cells at day 8. b-FGF blocked the mineralization activity of cementoblasts and addition of Dex was not able to override this effect. Comparing mineralization results with gene expression profile inhibition of mineralization by FGF correlated with an increase in levels of expression MGP and OPN mRNA and a decrease in levels of BSP and OCN mRNA. The increase in mineral formation by Dex correlated with an increase in BSP expression at short-term, which may result in increased BSP protein extracellularly, thereby providing the appropriate environment for promotion of mineralization. These differences, plus differences in other genes/proteins not examined; e.g., cell cycle regulators, most likely contribute to the significant differences observed in FGF versus Dex on mineral nodule formation.

\section{DISCUSSION}

Results from this investigation demonstrate that Dex and b-FGF, alone or in combination, have significant 


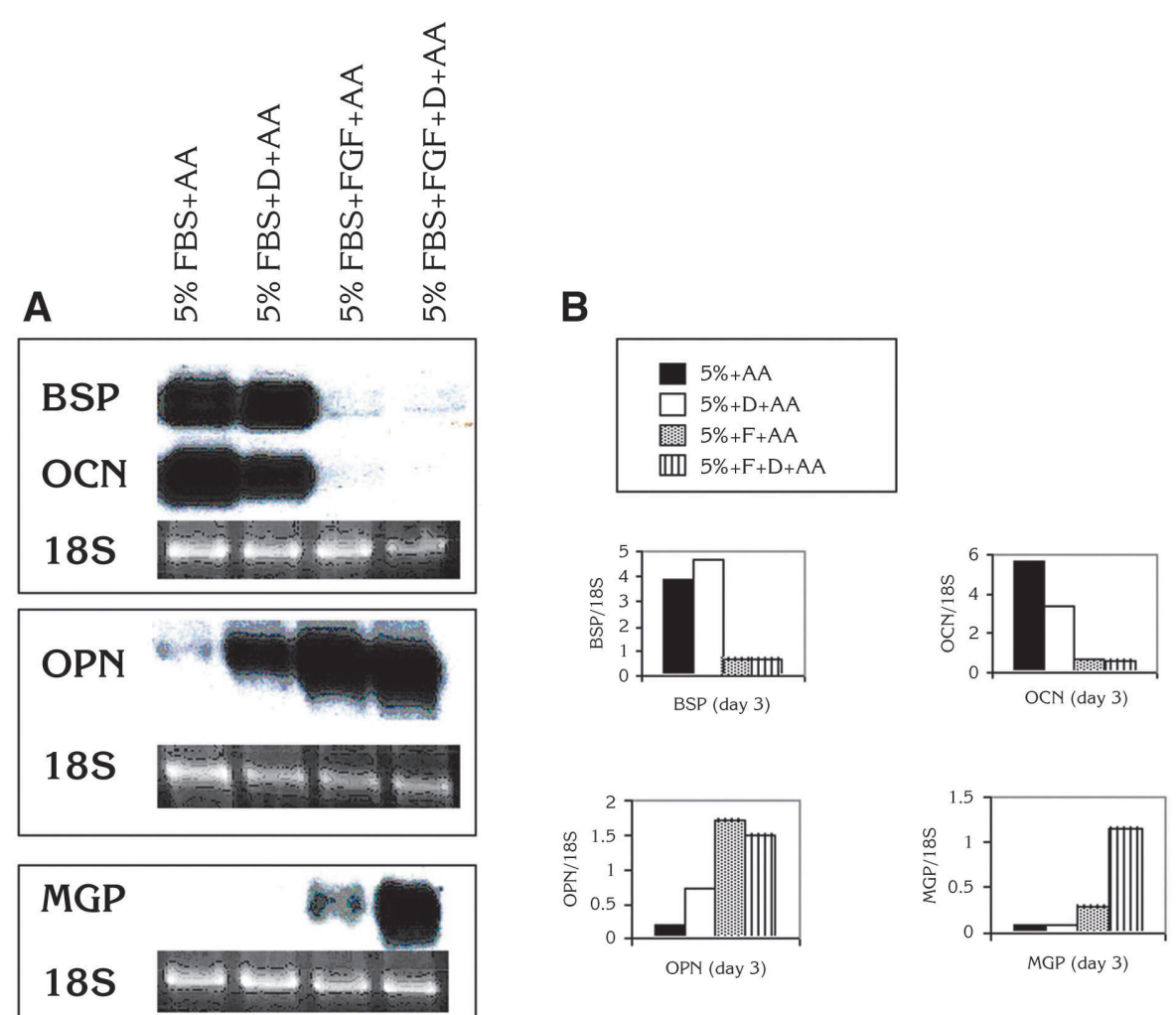

Figure 4.

Effect of Dex and/or b-FGF on gene expression by cementoblasts on day 3. A) Cementoblasts were grown in media containing 5\% FBS+AA, 5\% FBS+Dex+AA, 5\% FBS+b-FGF+AA, 5\% $F B S+D e x+b-F G F+A A$, and RNA was isolated on day 3. Gene expression for BSP, OCN, OPN, and MGP was determined by Northern blot analysis. I 85 was used to evaluate loading efficiency. Note increased expression of OPN in cementoblasts exposed to Dex, b-FGF, and Dex+b-FGF. $b$-FGF and Dex+b-FGF increased MGP transcripts at this time point. Importantly, the combination of these agents resulted in a higher level of MGP expression than b-FGF alone. Dex, b-FGF, and Dex+b-FGF downregulated OCN mRNA expression while b-FGF decreased transcripts for BSP that were not altered by addition of Dex. B) Normalization expressed as gene// $8 \mathrm{~S}$ band (RNA gel). These results were noted in two separate experiments. phosphate that failed to mature into hydroxyapatite. ${ }^{51}$ The lack of expression of an osteoblast/cementoblast phenotype in our studies may reflect differences in response of diverse cell types and/or diverse stages of maturation to b-FGF and/ or Dex, and/or may be a result of differences in experimental design. In addition, von Kossa assay was used for our studies, with inherent limitations in this assay system in terms of evaluating physiologic linked mineralization.

In support of the results presented here, Pitaru et al. suggested that b-FGF may serve a therapeutic function by increasing the progenitor pool of the periodontium (of special importance, since periodontitis often occurs in older individuals, who exhibit a considerable decrease in the number of mineralized tissue progenitor cells within the periodontium), and by the capacity of these progenitor cells to produce mineralized-like nodules. ${ }^{52}$ Additionally, Sato et al. investigated the effect of b-FGF for its ability to promote regeneration of cementum and periodontal ligament using a beagle dog model, in which they applied b-FGF in a collagen gel to the experimentally induced defects in the middle part of the root surfaces. ${ }^{53}$ Eight weeks after removal of cementum and PDL, they observed formation of dense fibers

effects on cementoblast behavior in vitro, including changes in gene expression, mineralization ability, and cell morphology. In our model, b-FGF treatment alone abolished cementoblast-mediated mineral nodule formation, while Dex alone markedly increased mineralization by cementoblasts.

Many of these findings are as predicted based on studies from other groups using different models; e.g., increased cell proliferation with b-FGF, mineral promotion with Dex. ${ }^{21,32-35,49,50}$ However, some previous studies have resulted in very different findings from the ones presented here. For example, Pri-Chen et al. reported that b-FGF enhanced both cell growth and expression of the osteogenic phenotype in Dextreated human bone marrow-derived bone-like cells in culture, including increased mineral nodule formation. ${ }^{33}$ Studies reported by Chaudhary et al. also revealed mineral deposition with b-FGF alone, however this was found to be amorphous octacalcium bound to the alveolar bone and newly synthesized cementum on the denuded dentin of teeth treated with $1 \mu \mathrm{g}$ of b-FGF. ${ }^{53}$ Thus, using b-FGF may be valuable for increasing regenerative outcomes of periodontal therapy, especially in difficult areas such as 1- or 2wall defects and furcation problems where vascularization may impede the regenerative potential.

In addition to predicted behavior of FGF and Dex, our data revealed some exciting new findings, suggesting synergisms between b-FGF and Dex. MGP expression was not observed in control or Dex-treated cultures, but cells exposed to b-FGF expressed transcripts for MGP, and the addition of Dex to b-FGF treated cells markedly enhanced this expression. Since MGP is thought to regulate crystal growth, the ability of b-FGF in combination with Dex to override the positive effect of Dex alone on cementoblast-mediated mineralization may be related to additive effects of these to agents on cell behavior. 


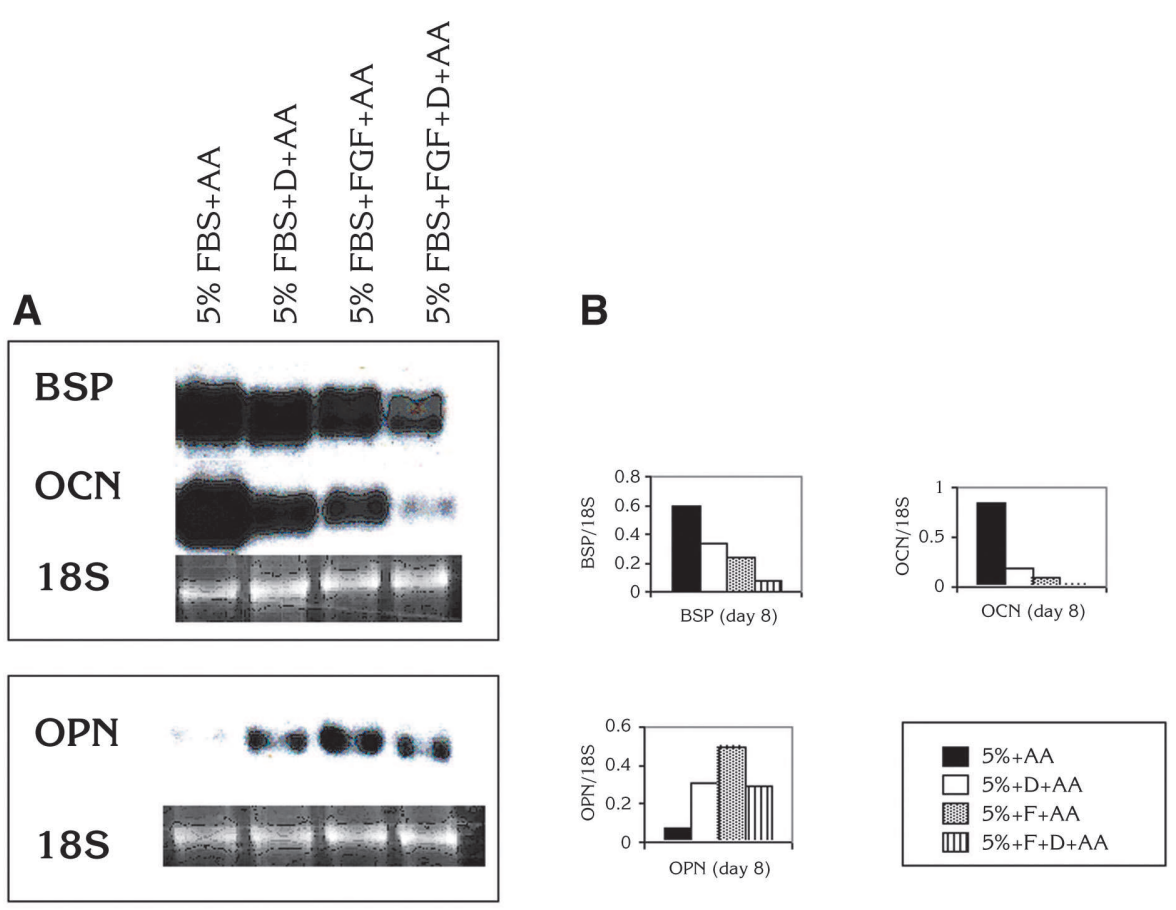

Figure 5.

Effect of Dex and/or b-FGF on gene expression by cementoblasts on day 8. A) Cementoblasts were incubated in media containing $5 \% \mathrm{FBS}+\mathrm{AA}, 5 \% \mathrm{FBS}+\mathrm{Dex}+\mathrm{AA}, 5 \% \mathrm{FBS}+\mathrm{B}-\mathrm{FGF}+\mathrm{AA}, 5 \%$ $F B S+D e x+b-F G F+A A$, and RNA was isolated on day 8. Gene expression for BSP, OCN, OPN, and MGP was determined by Northern analysis. I 85 was used to evaluate loading efficiency. An increase in OPN mRNA levels and a decrease BSP and OCN mRNA levels were noted in all treated groups compared to $5 \%$ FBS+AA groups. Note increased expression of OPN in cementoblasts exposed to Dex, b-FGF and Dex+b-FGF.MGP transcripts were not apparent at this time. B) Normalization expressed as gene/l 8S band (RNA gel). These results were noted in two separate experiments.
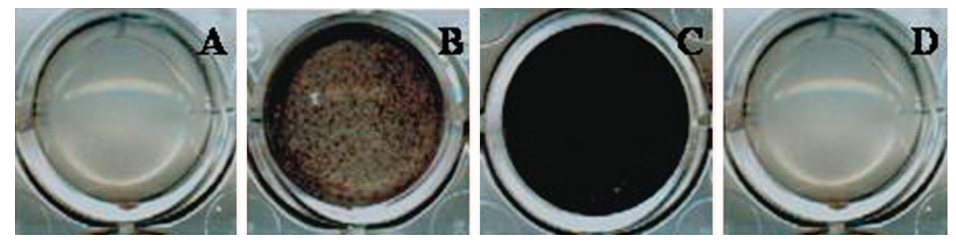

Figure 6.

von Kossa staining was used to determine mineral nodule formation on day 8 . For these studies, cells were cultured in media containing: $\boldsymbol{A}) 5 \% \mathrm{FBS}+\beta$-glycerophoshate $(\beta-G P, 10 \mathrm{mM}) ; \mathbf{B}) 5 \%$ $\left.F B S+A A(50 \mu \mathrm{g} / \mathrm{ml})+\beta-G P ; \boldsymbol{C}) 5 \% \mathrm{FBS}+\mathrm{Dex}\left(10^{-7} \mathrm{M}\right)+A A+\beta-G P ; \boldsymbol{D}\right) 5 \% \mathrm{FBS}+b-F G F$ $(50 \mathrm{ng} / \mathrm{ml})+A A+\beta-G P$; and E) $5 \%$ FBS $+\operatorname{Dex}\left(10^{-7} \mathrm{M}\right)+b-F G F(50 \mathrm{ng} / \mathrm{ml})+A A+\beta$-GP. Note increased mineral nodule formation in Dex-treated cementoblasts. b-FGF treatment prevented nodule formation that was not altered by addition of Dex. Representative experiment shown here where results were reproduced in three independent experiments.

Another interesting finding was the dramatic decrease in BSP and OCN mRNA levels in b-FGF treatment alone, or in b-FGF plus Dex treated cells, when compared to the control group (5\% FBS+AA) (Figs. 4 and 5). Additionally, there was an increase in OPN mRNA expression, seen from 6 hours to 3 days, under these conditions. Although the exact role of OCN in

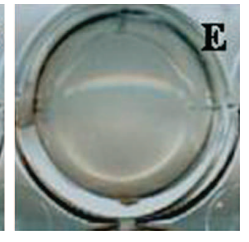

bone metabolism is not clear, it is known to be a marker for cells undergoing mineralization, and is thought to play a role in bone remodeling. ${ }^{54}$ Existing data suggest that both OPN and OCN may act in limiting the extent of bone mineralization. ${ }^{46,55}$ Saygin et al. demonstrated that exposure of cementoblasts to PDGF-BB resulted in a decrease in BSP and OCN mRNA and increased expression of OPN mRNA, and that mineralization of cementoblasts was inhibited by continuous application of PDGF-BB. ${ }^{5}$ Similar to these studies, we observed increased OPN mRNA and decreased BSP and OCN mRNA expression with accompanying inhibition of mineralization in cementoblasts treated with b-FGF alone or in combination with Dex. In contrast, Dex treatment alone did not result in a decrease in BSP expression early on, which may explain, in part, the enhancement of mineralization with Dex treatment as compared to control or b-FGF treatment.

Furthermore, a strong association between MGP mRNA expression and inhibition of mineralization was noted in cells treated with FGF alone or plus Dex. MGP is a mineral binding protein synthesized by vascular smooth muscle cells and by chondrocytes that produce an uncalcified extracellular matrix. Mice that lack MGP develop to term, but die within 2 months as a result of arterial calcification. ${ }^{56}$ MGPdeficient mice additionally exhibit inappropriate calcification of cartilage, including the growth plate, resulting in short stature, osteopenia, and fractures. ${ }^{57}$ Gopalakrishnan et al. reported that local injection of PTH over the calvaria of mice induced a 2 -fold increase in MGP mRNA. In a concurrent in vitro study using MC3T3-E1 murine preosteoblasts, MGP was shown to be induced 3 hours after PTH treatment, with a 6- to 8-fold induction seen after 6 hours, and OPN (an in vitro inhibitor of mineralization) was induced approximately 4 -fold after 12 hours of PTH treatment. ${ }^{58}$

In the current study, when cementoblasts were treated with b-FGF or b-FGF+Dex, transcripts for MGP were observed as early as 6 hours, and no mineralization 
was observed in either group by day 8 . The inhibition of mineralization induced by in vitro b-FGF or b-FGF+Dex treatment in cementoblasts may be explained in part by stimulation in transcripts for both OPN and MGP. The dramatic increase of MGP with the combination of FGF and Dex, especially considering the fact that Dex treatment alone results in an enhancement of mineralization over control, suggests that MGP may play a critical role in the inhibiting mineral nodule formation.

Although there are always limitations with in vitro models, especially with regard to the effects of agents in vitro versus in vivo, in vitro studies are of value in identifying possible mechanisms by which agents may affect cell behavior in vivo and thus establish a foundation for clinical trials. Our results indicate that dose selection and timing for delivery of agents are critical when considering the use of more than one factor clinically to regenerate periodontal tissues. For example, b-FGF had a positive effect on proliferation, but a potentially negative effect on mineralization. In contrast, Dex promoted nodule formation, but Dex $+b-F G F$ resulted in negative mineralization. These studies, and those of others, ${ }^{32-35,49-52}$ highlight the complex response of cells to specific factors. Continued research focused on investigating the genes/proteins regulating cell function, and the influence of factors alone and in combination, is vital to obtaining information required to design clinical therapies based on sound scientific principles. Further in vivo studies are required to determine whether these two factors have beneficial effects for obtaining periodontal regeneration when used separately or in combination.

\section{ACKNOWLEDGMENTS}

This study was supported by The Scientific and Technical Research Council of Turkey (TUBITAK/BAYG) and Research Foundation of Hacettepe University, Turkey, and NIDCR grant DE09532. TUBITAK DNA/Cell Bank $\mathcal{E}$ Gene Research Laboratory facilities in Ankara, Turkey, were used for some of the cell culture work.

\section{REFERENCES}

1. American Academy of Periodontology. The potential role of growth and differentiation factors in periodontal regeneration (position paper). J Periodontol 1996;67:545-553.

2. Somerman MJ, Ouyang H, Berry JE, et al. Evaluation of periodontal regeneration: From the root's point of view. J Periodontal Res 1999;34:420-424.

3. Giannobile WV. Periodontal tissue regeneration by polypeptide growth factors and gene transfer. In: Lynch SE, Genco RJ, Marks RE, eds. Tissue Engineering: Applications in Maxillofacial Surgery and Periodontics, vol. 1. Chicago: Quintessence; 1999:231-243.

4. Parkar MH, Kuru L, Giouzeli M, Olsen I. Expression of growth-factor receptors in normal and regenerating human periodontal cells. Arch Oral Biol 2001;46:275-284.

5. Saygin NE, Tokiyasu Y, Giannobile WV, Somerman MJ. Growth factors regulate expression of mineral associated genes in cementoblasts. J Periodontol 2000;71:1591-1600.
6. Tokiyasu Y, Saygin NE, Somerman MJ. Enamel factors regulate expression of genes associated with cementoblasts. J Periodontol 2000;71:1829-1839.

7. Saygin NE, Giannobile WV, Somerman MJ. Molecular and cell biology of cementum. Periodontol 2000 2000;24:73-98.

8. Giannobile WV, Meraw SJ. Periodontal applications. In: Methods of Tissue Engineering. San Diego: Academic Press; 2001:1205-1215.

9. Cochran DL, Wozney JM. Biologic mediators for periodontal regeneration. Periodontol 2000 1999;19:40-58.

10. Mumford JH, Carnes DL, Cochran DL, Oates TW. The effects of platelet-derived growth factor-BB on periodontal cells in an in vitro wound model. $J$ Periodontol 2001;72:331-340.

11. Zhu Z, Lee CS, Tajeda KM, Giannobile WV. Gene transfer and expression of platelet-derived growth factor modulate periodontal cellular activity. J Dent Res 2002;80:892-897.

12. Gaston NK, Cochran DL. Factors that modulate the effects of bone morphogenetic protein-induced periodontal regeneration. A critical review. J Periodontol 2002;73:925-936.

13. Marie PJ. Fibroblast growth factor signaling controlling osteoblast differentiation. Gene 2003;316:23-32.

14. Lieberman JR, Daluiski A, Einhorn TA. The role of growth factors in the repair of bone. J Bone Joint Surg 2002;84:1032-1044.

15. Hurley MM, Marie PJ, Florkiewicz RZ. Fibroblast growth factor (FGF) and FGF receptor families in bone. In: Bilezikian JP, Raisz LG, Rodan GA, eds. Principles of Bone Biology. San Diego: Academic Press; 2002;825-851.

16. Zellin G, Linde A. Effects of recombinant human fibroblast growth factor- 2 on osteogenic cell population during orthopic osteogenesis in vitro. Bone 2000;26:161-168.

17. Khan SN, Bostrom MPG, Lane JM. Bone growth factors. Orthop Clin N Am 2000;31:375-387.

18. Nakajima A, Nakajima F, Shimizu S, et al. Spatial and temporal gene expression for fibroblast growth factor type I receptor (FGFR1) during fracture healing in the rat. Bone 2001;29:458-466.

19. Shimazu A, Bachchu MAH, Morishita M, et al. Expression of syndecan-2, -4 and fibroblast growth factor receptor type 1 in human periodontal ligament fibroblasts and down-regulation of these membrane proteins during maturation in culture. J Dent Res 1999;78:1791-1799.

20. Takayama S, Murakami S, Nozaki T, et al. Expression of receptors for basic fibroblast growth factor on human periodontal ligament cells. J Periodontal Res 1998;33:315-322.

21. Takayama S, Murakami S, Miki Y, et al. Effects of basicfibroblast growth factor on human periodontal ligament cells. J Periodontal Res 1997;32:667-675.

22. Gao J, Jordan TW, Cutress TW. Immunolocalization of basic-fibroblast growth factor (b-FGF) in human periodontal ligament (PDL) tissue. J Periodontal Res 1996;31:260-264.

23. Murakami S, Takayama S, Ikezawa K, et al. Regeneration of periodontal tissues by basic fibroblast growth factor. J Periodontal Res 1999;34:425-430.

24. Takayama S, Murakami S, Shimabukuro Y, Kitamura M, Okada H. Periodontal regeneration by FGF-2 (b-FGF) in primate models. J Dent Res 2001;80:2075-2079.

25. Murakami S, Takayama S, Kitamura M, et al. Recombinant human basic fibroblast growth factor (b-FGF) stimulates periodontal regeneration in Class II furcation defects created in beagle dogs. J Periodontal Res 2003;38:97-103.

26. Nakahara T, Nakamura T, Kobayashi E, et al. Novel approach to regeneration of periodontal tissues based on in situ tissue engineering: Effects of controlled release of basic fibroblast growth factor from a sandwich membrane. Tissue Eng 2003;9:153-162. 
27. Jaye M, Schlessinger J, Dionne CA. Fibroblast growth factor receptor tyrosine kinases: Molecular analysis and signal transduction. Biochimica et Biophysica Acta 1992;1135:185-199.

28. Folkman J, Klagsbrun M. Angiogenic factors. Science 1987;235:442-447.

29. Rutherford RB, TrailSmith MD, Ryan ME, Charette MF. Synergistic effects of dexamethasone on platelet-derived growth factor mitogenesis in vitro. Arch Oral Biol 1992;37:139-145.

30. Rutherford RB, Ryan ME, Kennedy JE, Tucker MM, Charette MF. Platelet-derived growth factor and dexamethasone combined with a collagen matrix induce regeneration of the periodontium in monkeys. $J$ Clin Periodontol 1993;20:537-544.

31. Nohutcu RM, Somerman MJ, McCauley LK. Dexamethasone enhances the effects of parathyroid hormone on human periodontal ligament cells in vitro. Calcif Tissue Int 1995;56:571-577.

32. Pitaru S, Kotev-Emeth SK, Noff D, et al. Effects of basic fibroblast growth factor on the growth and differentiation of adult stromal bone marrow cells: Enhanced development of mineralized bone-like tissue in culture. J Bone Min Res 1993;8:919-929.

33. Pri-Chen S, Pitaru S, Lokiec F, Savion N. Basic fibroblast growth factor enhances the growth and expression of the osteogenic phenotype of dexamethasone-treated human bone marrow-derived bone-like cells in culture. Bone 1998;23:111-117.

34. Kotev-Emeth S, Savion N, Pri-Chen S, Pitaru S. Effect of maturation on the osteogenic response of cultured stromal bone marrow cells to basic fibroblast growth factor. Bone 2000;27:777-783.

35. Scutt A, Bertram P. Basic fibroblast growth factor in the presence of dexamethasone stimulates colony formation, expansion and osteoblastic differentiation by rat bone marrow stromal cells. Calcif Tissue Int 1999;64: 69-77.

36. D'Errico JA, Berry JE, Ouyang H, Strayhorn CL, Windle JJ, Somerman MJ. Employing a transgenic animal model to obtain cementoblasts in vitro. J Periodontol 2000;71:63-72.

37. D'Errico JA, MacNeil RL, Takata T, Berry JE, Strayhorn C, Somerman MJ. Expression of bone associated markers by tooth root lining cells, in situ and in vitro. Bone 1997;20:117-126.

38. D'Errico JA, Ouyang H, Berry JE, et al. Immortalized cementoblasts and periodontal ligament cells in culture. Bone 1999;25:39-47.

39. Chen D, Chen H, Feng JQ, et al. Osteoblastic cell lines derived from a transgenic mouse containing the osteocalcin promoter driving SV T-antigen. Mol Cell Diff 1995; 3:193-212.

40. Walsh S, Jordan GR, Jefferiss C, Stewart K, Bereshord JN. High concentrations of dexamethasone suppress the proliferation but not the differentiation or further maturation of human osteoblast precursors in vitro: Relevance to glucocorticoid-induced osteoporosis. Rheumatology 2001;40:74-83

41. Yamanouchi K, Satomura K, Gotoh Y, et al. Bone formation by transplanted human osteoblasts cultured within collagen sponge with dexamethasone in vitro. J Bone Miner Res 2001;16:857-867.

42. Nohutcu RM, McCauley LK, Koh AJ, Somerman MJ. Expression of extracellular matrix proteins in human periodontal ligament cells during mineralization in vitro. J Periodontol 1997;68:320-327.
43. Young MF, Ibaraki K, Kerr JM, Lyu MS, Kozak CA. Murine bone sialoprotein (BSP): cDNA cloning, mRNA expression, and genetic mapping. Mamm Genome 1994;5:108-111.

44. Young MF, Kerr JM, Termine JD, et al. cDNA cloning, mRNA distribution and heterogeneity, chromosomal location, and RFLP analysis of human osteopontin (OPN). Genomics 1990;7:491-502.

45. Celeste AJ, Rosen V, Buecker JL, Kriz R, Wang EA, Wozney JM. Isolation of the human gene for bone gla protein utilizing mouse and rat cDNA clones. Embo $J$ 1986;5:1885-1890.

46. Ducy P, Karsenty G. Skeletal Gla proteins: Gene structure, regulation of expression, and function. In: Bilezikian JP, Raisz LG, Rodan GA, eds. Principles of Bone Biology. San Diego: Academic Press; 1996:183-196.

47. Franceschi RT, Iyer BS, Chi Y. Effects of ascorbic acid on collagen matrix formation and osteoblast differentiation in murine MC3T3-E1 cells. J Bone Miner Res 1994;9:843-854.

48. Puchtler HMS. Demonstration of phosphates in calcium deposits: A modification of von Kossa's reaction. Histochem 1978;56:177-185.

49. Coelho MJ, Fernandes MH. Human bone cell cultures in biocompatibility testing. Part II: Effects of ascorbic acid, $\beta$-glycerophosphate and dexamethasone on osteoblastic differentiation. Biomaterials 2000;21:1095-1102.

50. Ogstan N, Harrison AJ, Cheung HFJ, Ashton BA, Hampson G. Dexamethasone and retinoic acid differentially regulate growth and differentiation in an immortalized human clonal bone marrow stromal cell line with osteoblastic characteristics. Steroids 2002;67:895-906.

51. Chaudhary LR, Hofmeister AM, Hruska KA. Differential growth factor control of bone formation through osteoprogenitor differentiation. Bone 2004;34:402-411.

52. Pitaru S, Naraynan SA, Kotev-Emeth S, et al. The effect of age on the expression of mineralized tissue progenitors in the periodontium-the effect of bFGF. $J$ Periodontal Res 1997;32:179-182.

53. Sato Y, Kikuchi M, Ohata N, Tamura M, Kuboki Y. Enhanced cementum formation in experimentally induced cementum defects of the root surface with the application of recombinant basic-fibroblast growth factor in collagen gel in vivo. J Periodontol 2004;75:243-248.

54. Hunter GK, Hauschka PV, Poole AR, Rosenberg LC, Goldberg HA. Nucleation and inhibition of hydroxyapatite formation by mineralized tissue proteins. Biochem $J$ 1996;317:59-64.

55. Noda M, Denhardt D. Osteopontin. In: Bilezikian JP, Raisz LG, Rodan GA, eds. Principles of Bone Biology, 2nd ed., vol. I. San Diego: Academic Press; 2002:239-250.

56. Luo G, Ducy P, McKee MD, et al. Spontaneous calcification of arteries and cartilage in mice lacking matrix gla protein. Nature 1997;386:78-81.

57. Luo G, D'Souza R, Hogue D, Karsenty G. The matrix gla protein is a marker of the chondrogenesis cell lineage during mouse development. J Bone Min Res 1995;10:325-334.

58. Gopalakrishnan R, Ouyang H, Somerman MJ, McCauley LK, Franceschi RT. Matrix gamma-carboxyglutamic acid protein is a key regulator of PTH-mediated inhibition of mineralization in MC3T3-E1 osteoblast-like cells. Endocrinology 2001;142:4379-4388.

Correspondence: Dr. Sema S. Hakki, Selcuk University, Faculty of Dentistry, Department of Periodontology, Campus, 42079, Konya, Turkey. Fax: 90-332-241-0062; e-mail: sshakki@selcuk.edu.tr or sshakki@yahoo.com.

Accepted for publication February 9, 2005. 